\title{
Glutamina e turnover do carbono no tecido adiposo de leitões
}

\author{
Fabiana Ribeiro Caldara ${ }^{(1)}$, Carlos Ducatti(2), Dirlei Antonio Berto(3), Juliana Célia Denadai( ${ }^{(3)}$, \\ Gustavo Augusto Andrade ${ }^{(1)}$ e Marilú Martins Gioso(1)
}

\begin{abstract}
(1)Universidade José do Rosário Vellano, Dep. de Ciências Agrárias, Rod. MG 179, Km 0, CEP 37130-000 Alfenas, MG. E-mail: fabi_caldara@yahoo.com.br, gustavo.andrade@unifenas.br, mmgioso@yahoo.com.br (2)Universidade Estadual Paulista (Unesp), Centro de Isótopos Estáveis, Instituto de Biociências, Distrito de Rubião Júnior, s/no, CEP 18618-000 Botucatu, SP. E-mail: ducatti@ibb.unesp.br (3)Unesp, Dep. de Produção e Exploração Animal, Fac. de Medicina Veterinária e Zootecnia. E-mail: dirleiberto@fca.unesp.br, denadaijc@gmail.com
\end{abstract}

Resumo - O objetivo deste estudo foi avaliar a influência da glutamina no turnover do carbono do tecido adiposo de leitões. Quarenta leitões foram desmamados aos 21 dias e distribuídos, aleatoriamente, em dois tratamentos: T1, dieta de plantas $C_{3}$, sem suplementação de glutamina; e T2, dieta de plantas $C_{3}$, suplementada com $1 \%$ de glutamina. Nos dias $0,1,3,5,8,11,15,20,29$ e 46 pós-desmame, dois leitões por tratamento foram abatidos; amostras de tecido adiposo foram coletadas e analisadas quanto à composição isotópica em $\delta \%{ }^{13} \mathrm{C}$, e foi mensurada a substituição do carbono em função do tempo. Na primeira semana pós-desmame, não houve alteração dos valores isotópicos, pois os animais nessa fase usam suas reservas corporais de gordura. Após esse período, o tecido adiposo começou a incorporar o sinal isotópico da ração, o que indica início da deposição de gordura corporal. Nos animais que se alimentaram com suplemento de glutamina, a incorporação do carbono da ração no tecido adiposo foi mais rápida. As reservas de gordura corporal, adquiridas durante o aleitamento, exercem importante papel na manutenção dos animais por aproximadamente uma semana pós-desmame, e a glutamina auxilia na retomada de deposição de gordura corporal após esse período.

Termos para indexação: carbono-13, desmame, glutamina, reserva corporal, suíno.

\section{Glutamine and carbon turnover in adipose tissue of piglets}

\begin{abstract}
The objective of this work was to verify the glutamine influence on carbon turnover of adipose tissue of piglets. Forty piglets were weaned on the $21^{\text {st }}$ day, and were distributed, at random, into two treatments: $\mathrm{T} 1$, diet of $\mathrm{C}_{3}$ plants, without glutamine supplementation; and $\mathrm{T} 2$, diet of $\mathrm{C}_{3}$ plants, supplemented with $1 \%$ glutamine. On days $0,1,3,5,8,11,15,20,29$ and 46 postweaning, two piglets by treatment were slaughtered; samples of the adipose tissue were collected and analyzed as for their carbon isotopic composition $\left(\delta \%{ }^{13} \mathrm{C}\right)$, and carbon substitution was measured, in function of time. In the first week postweaning, there was no alteration of the isotopic values, because the animals in this phase used their fat corporal reserve. After this period, the adipose tissue began to incorporate the isotopic signal of the ration, which indicates the onset of body fat deposition. In animals supplemented with glutamine, carbon incorporation in the fatty tissue was faster. Fat reserve acquired during the suckling period have an important role in the maintenance of the animals, during approximately one week postweaning; and glutamine helps in body fat deposition retaking after this period.
\end{abstract}

Index terms: carbon-13, weaning, glutamine, corporal reserve, swine.

\section{Introdução}

Na produção intensiva de suínos, o desmame dos leitões com 21 dias de idade ou menos é atualmente uma prática comum, por permitir maior produtividade das matrizes. O desmame nessa idade requer que seja atendida uma série de necessidades relativas à nutrição, em razão da imaturidade de sistema digestório do animal.

Nos três a cinco primeiros dias pós-desmame, os leitões não conseguem ingerir alimento suficiente para atender suas necessidades energéticas de manutenção, e aos dez dias pós-desmame, ainda não recuperaram a ingestão de energia de antes do desmame e, então, usam suas reservas de gordura corporal nesse período. Isto impede que o leitão alcance seu máximo potencial de crescimento, no início desse período. Leitões que mantêm ou perdem peso, durante a primeira semana pós-desmame, permanecem cerca de dez dias a mais na engorda, para atingir o peso de abate, com significativas implicações econômicas na produção de suínos (Mavromichalis, 2001). 
Significativa quantidade de glutamina é utilizada diariamente por vários tecidos corporais (intestino, pâncreas, baço, rim, cérebro etc.). Para manter constante a concentração de glutamina circulante, é necessário que a mesma quantidade seja sintetizada por outros órgãos (Tizianello et al., 1978).

O tecido adiposo geralmente não tem sido considerado importante no metabolismo de aminoácidos. Porém, estudos mostraram que o carbono-14 de leucina ou alanina pode ser incorporado em triacilglicerol, em tecido adiposo isolado (Feller, 1965), e que aminoácidos de cadeia ramificada são metabolizados por tecido adiposo isolado, com síntese de glutamina e alanina (Tischler \& Goldberg, 1980), o que indica que o tecido adiposo metaboliza aminoácidos de maneira similar ao músculo esquelético, com a capacidade adicional de converter parte do carbono em triacilglicerol (Newsholme \& Leech, 1983).

$\mathrm{Se}$ as condições para lipogênese e formação de triacilglicerol são favoráveis, a maior parte da glutamina removida pelo tecido adiposo é convertida em glutamato que, posteriormente, é metabolizado para acetil-CoA, para prover precursor para a lipogênese (Kowalchuk et al., 1988).

Vários aminoácidos são capazes de estimular a lipogênese em hepatócitos de ratos. Quando hepatócitos foram incubados em presença de glicose, a glutamina foi o aminoácido de maior eficiência no estímulo da lipogênese (Baquet et al., 1991). Entretanto, em cães mantidos em jejum por quatro dias, a infusão de glutamina atuou como potente inibidor da lipólise (Cersosimo et al., 1986).

A aplicação dos isótopos estáveis como traçadores naturais, em pesquisas na área de nutrição animal, vem aumentando nas últimas décadas. Esta técnica é indicada em situações em que fontes dietéticas, isotopicamente distintas, estão disponíveis para os animais, uma vez que a composição isotópica dos tecidos e fluídos corporais depende principalmente de sua alimentação. Assim, dietas com assinaturas isotópicas distintas podem ser usadas para medir taxas de turnover, em todos os tecidos corporais do animal.

A diferença natural, de $14 \%$ o mais rica em ${ }^{13} \mathrm{C}$, em plantas do ciclo fotossintético $\mathrm{C}_{4}$, em relação às plantas do ciclo $\mathrm{C}_{3}$, possibilita utilizar essas plantas e seus subprodutos como traçadores naturais em animais, sem a necessidade de síntese de compostos enriquecidos em carbono-13 ou a utilização de isótopos radioativos (Metges et al., 1990).
O objetivo deste estudo foi avaliar a influência da glutamina sobre o turnover do carbono em tecido adiposo de leitões, após o desmame, utilizando-se a técnica dos isótopos estáveis e a variação natural de carbono-13 existente entre plantas de diferentes ciclos fotossintéticos.

\section{Material e Métodos}

O experimento foi conduzido no Setor de Suinocultura, Faculdade de Medicina Veterinária e Zootecnia (FMVZ), Universidade Estadual Paulista, Botucatu, SP.

Matrizes da raça Large White $(n=9)$ foram cobertas e passaram a receber ração composta, predominantemente, por grãos de plantas do ciclo fotossintético $\mathrm{C}_{4}$, durante toda a gestação e lactação. Este procedimento foi adotado para que, ao nascer, os leitões possuíssem em seus tecidos corporais o sinal isotópico semelhante ao dessas dietas. Foram coletadas amostras de leite de cinco porcas, ao longo do período de lactação, para o monitoramento do sinal isotópico de carbono-13.

Os leitões $(n=40)$ foram desmamados aos 21 dias de idade e alojados em galpões de creche, distribuídos em gaiolas metálicas suspensas $(1 \times 1,75 \mathrm{~m})$ com piso ripado de plástico, equipadas com comedouro metálico automático, bebedouro tipo chupeta e campânula de aquecimento.

A partir do desmame, os animais passaram a receber ração composta predominantemente por grãos de plantas do ciclo fotossintético $\mathrm{C}_{3}$, com o sinal isotópico de carbono-13 distinto das rações fornecidas às matrizes. $\mathrm{O}$ programa de alimentação foi dividido em duas fases: a primeira de 0 a 14 dias pósdesmame (pré-inicial), e a segunda dos 15 aos 46 dias pós-desmame (inicial). $\mathrm{O}$ alimento foi fornecido à vontade.

Todas as rações foram formuladas para atender às exigências nutricionais propostas pelo National Research Council (1998), e suas composições nutricionais e isotópicas podem ser observadas na Tabela 1 . Os valores isotópicos (\%o) dos ingredientes usados na ração foram: milho $(-12,45)$, farelo de soja $(-26,56)$, farelo de trigo $(-27,66)$, farinha de trigo $(-26,43)$.

Os leitões foram distribuídos ao acaso, em dois tratamentos (20 animais por tratamento): $\mathrm{T}_{1}$, dieta predominantemente $\mathrm{C}_{3}$, sem suplementação de glutamina (controle); $\mathrm{T}_{2}$, dieta controle, suplementada com $1 \%$ de glutamina (glutamina). 
Aos $0,1,3,5,8,11,15,20,29$ e 46 dias após o desmame, foram tomados, ao acaso, dois leitões por tratamento que, após insensibilização, foram abatidos por sangria, por meio de incisão da veia jugular. O dia zero tem por objetivo expressar a composição isotópica do alimento consumido antes da troca; neste caso, a ração fornecida às matrizes e o leite consumido pelos leitões.

Após o abate, os animais foram eviscerados e, posteriormente, foram coletadas as amostras de tecido adiposo subcutâneo da região mandibular as quais foram acondicionadas, identificadas e imediatamente congeladas $\left(-18^{\circ} \mathrm{C}\right)$, até preparação para as análises isotópicas.

Para a realização das análises isotópicas, as amostras foram acondicionadas em cápsulas de estanho. Em virtude de a gordura ser muito rica em carbono, a quantidade de tecido utilizado para análise deve ser extremamente pequena e, para facilitar o preparo das cápsulas, as amostras foram mantidas em estufa de ventilação forçada a $60^{\circ} \mathrm{C}$ por 48 horas, para que atingissem estado líquido. Porém, apenas uma pequena fração de cada uma das amostras atingiu o estado líquido, da qual foi retirado o conteúdo mínimo a ser analisado.

As amostras foram analisadas em espectrômetro de massa de razões isotópicas, do Centro de Isótopos Estáveis Ambientais, do Instituto de Biociências da Unesp,
Campus de Botucatu. Os resultados foram expressos em $\delta \%{ }^{13} \mathrm{C}$, em relação ao padrão internacional (PDB), com erro de análise de $0,2 \%$, calculado pela equação: $\delta \% o^{13} \mathrm{C}_{(\text {amostra, padrão) }}=\left[\left(\mathrm{R}_{\text {amostra }} / \mathrm{R}_{\text {padrão }}\right)-1\right] \times 10^{3}$, em que: $\delta \%{ }^{13} \mathrm{C}$ é o enriquecimento da razão ${ }^{13} \mathrm{C} /{ }^{12} \mathrm{C}$ da amostra, em relação ao padrão; $\mathrm{R}$ é a razão isotópica $\left({ }^{13} \mathrm{C} /{ }^{12} \mathrm{C}\right)$ da amostra e do padrão.

Os dados isotópicos obtidos foram compilados em curva isotópica padrão, com auxílio do programa Origin 6.0 Professional (Microcal Software Original 6.0 Professional, 1999), e os resultados foram analisados pelo modelo sigmoidal de regressão de Boltzmann.

O Modelo de Boltzmann tem por equação geral a expressão:

$\mathrm{y}=\left[\mathrm{A}_{1}-\mathrm{A}_{2} /\left(1+\mathrm{e}^{\left(\chi-\chi_{0}\right) / \mathrm{dx}}\right)\right]+\mathrm{A}_{2}$,

em que: $\chi_{0}$ é o ponto de inflexão da sigmóide; $\mathrm{dx}$ é a constante de tempo; $\mathrm{A}_{1}$ é o valor inicial do eixo $\mathrm{Y} \rightarrow \mathrm{y}$ $(-\infty) ; \mathrm{A}_{2}$ é o valor final do eixo $\mathrm{Y} \rightarrow \mathrm{y}(+\infty)$

$\mathrm{O}$ valor de $\mathrm{Y}$, em $\chi_{0}$, é a metade da distância entre os dois valores limites $A_{1}$ e $A_{2}: y\left(\chi_{0}\right)=\left(A_{1}+A_{2}\right) / 2$. O valor de $Y$ muda drasticamente, conforme variações de $\mathrm{X}$. A magnitude destas variações é aproximadamente $\mathrm{dx}$.

Atribuindo-se a terminologia isotópica à equação geral de Boltzmann, tem-se:

$\delta^{13} \mathrm{C}(\mathrm{t})=\delta^{13} \mathrm{C}(\mathrm{f})+\left[\delta^{13} \mathrm{C}(\mathrm{i})-\delta^{13} \mathrm{C}(\mathrm{f}) /\left(1+\mathrm{e}^{\left(\mathrm{t}-\chi_{0}\right) / \mathrm{dx}}\right)\right]$,

Tabela 1. Composição porcentual, isotópica e nutricional das rações experimentais fornecidas nas diferentes fases.

\begin{tabular}{|c|c|c|c|c|}
\hline \multirow[t]{2}{*}{ Composição porcentual } & \multicolumn{4}{|c|}{ Fases } \\
\hline & Gestação & Lactação & Pré-inicial & Inicial \\
\hline Milho & 64,0 & 54,0 & - & - \\
\hline Farelo de soja & 12,0 & 21,0 & 18,6 & 23,5 \\
\hline Farelo de trigo & 20,0 & 9,0 & - & - \\
\hline Farinha de trigo $^{(1)}$ & - & - & 41,4 & 60,5 \\
\hline Concentrado/núcleo & 4,0 & 16,0 & 40,0 & 16,0 \\
\hline Total & 100,0 & 100,0 & 100,0 & 100,0 \\
\hline \multicolumn{5}{|l|}{ Composição isotópica } \\
\hline$\delta \%{ }^{13} \mathrm{C}$ estimado & $-17,12$ & $-18,81$ & $-25,01$ & $-26,05$ \\
\hline$\delta \%{ }^{13} \mathrm{C}$ analisado & $-17,12$ & $-19,26$ & $-24,87$ & $-25,37$ \\
\hline Suplemento vitamínico/mineral (\%o) & $-10,89$ & $-25,14$ & $-22,83$ & $-23,85$ \\
\hline \multicolumn{5}{|l|}{ Composição nutricional calculada ${ }^{(2)}$} \\
\hline $\mathrm{EM}\left(\mathrm{kcal} \mathrm{kg}^{-1}\right)$ & 2.981 & 3.200 & 3.404 & 3.293 \\
\hline $\mathrm{PB}(\%)$ & 14,6 & 19,0 & 20,3 & 21,7 \\
\hline Lisina $(\%)$ & 0,64 & 0,95 & 1,40 & 1,17 \\
\hline Metionina (\%) & 0,23 & 0,30 & 0,37 & 0,35 \\
\hline Triptofano $(\%)$ & 0,16 & 0,22 & 0,24 & 0,26 \\
\hline Cálcio (\%) & 1,21 & 1,11 & 0,89 & 0,90 \\
\hline P disponível (\%) & 0,40 & 0,42 & 0,46 & 0,44 \\
\hline Lactose $(\%)$ & - & - & 8,00 & 5,00 \\
\hline
\end{tabular}

(1)No tratamento com glutamina, nas rações pré-inicial e inicial, a glutamina substituiu (1\%) a farinha de trigo, sem alterações significativas nos valores nutricionais e isotópicos. ${ }^{(2)}$ Valores calculados com base na composição das matérias-primas (Rostagno et al., 2000) e composição de núcleos e concentrados, fornecidos pela empresa Maxi Nutrição Animal. 
em que: $\delta^{13} \mathrm{C}(\mathrm{i})$ é o enriquecimento relativo inicial no tecido, expressado em $\delta \%$; $\delta^{13} \mathrm{C}(\mathrm{f})$ é o enriquecimento relativo final no tecido, expressado em $\delta \%$; $\delta^{13} \mathrm{C}(\mathrm{t})$ é o enriquecimento relativo no tecido em qualquer tempo (t), expressado em $\delta \%$; $\chi_{0}$ é o ponto de inflexão da sigmóide, representa a meia-vida do carbono, expressada em unidade de tempo; dx é a constante de tempo, expressada em unidade de tempo; t é o tempo experimental, expressado em unidade de tempo (dias após o desmame).

A equação gerada permite a determinação do valor de $\delta \% 0^{13} \mathrm{C}$, em tecido adiposo de leitões, em qualquer tempo $(\mathrm{t})$ desejado. Inseriu-se esta equação na expressão da diluição isotópica a seguir:

$\delta \mathrm{a}(\mathrm{A})+\delta \mathrm{b}(\mathrm{B})=\delta \mathrm{P}, \operatorname{com} \mathrm{A}+\mathrm{B}=1$,

em que: $\delta$ a é o valor do $\delta \% o^{13} \mathrm{C}$ da fonte de carbono pré-desmame (leite $\mathrm{C}_{4}$ ), expressado em $(\%$ ); $\delta$ b é o valor do $\delta \%{ }^{13} \mathrm{C}$ da fonte de carbono pós-desmame (ração $\mathrm{C}_{3}$ ), expressado em (\%o); $\delta \mathrm{P}$ é o valor do $\delta \%{ }^{13} \mathrm{C}$ do produto analisado (tecido adiposo), expressado em (\%o); A é a proporção da fonte de carbono pré-desmame (leite $\mathrm{C}_{4}$ ) no produto; $\mathrm{B}$ é a proporção da fonte de carbono pós-desmame (ração $\mathrm{C}_{3}$ ) no produto.

Assim: $\delta^{13} \mathrm{Ci}(\mathrm{A})+\delta^{13} \mathrm{Cf}(\mathrm{B})=\delta^{13} \mathrm{Cf}+\left[\delta^{13} \mathrm{Ci}-\right.$ $\left.\left.\delta^{13} \mathrm{Cf} /\left(1+\mathrm{e}^{(\mathrm{t}-\mathrm{x})}\right) / \mathrm{dx}\right)\right]$. Como $\mathrm{A}+\mathrm{B}=1$, tem-se que $A=1-B$, então: $B=1-\left[1 /\left(1+e^{\left(t-x_{0}\right) / d x}\right)\right]$

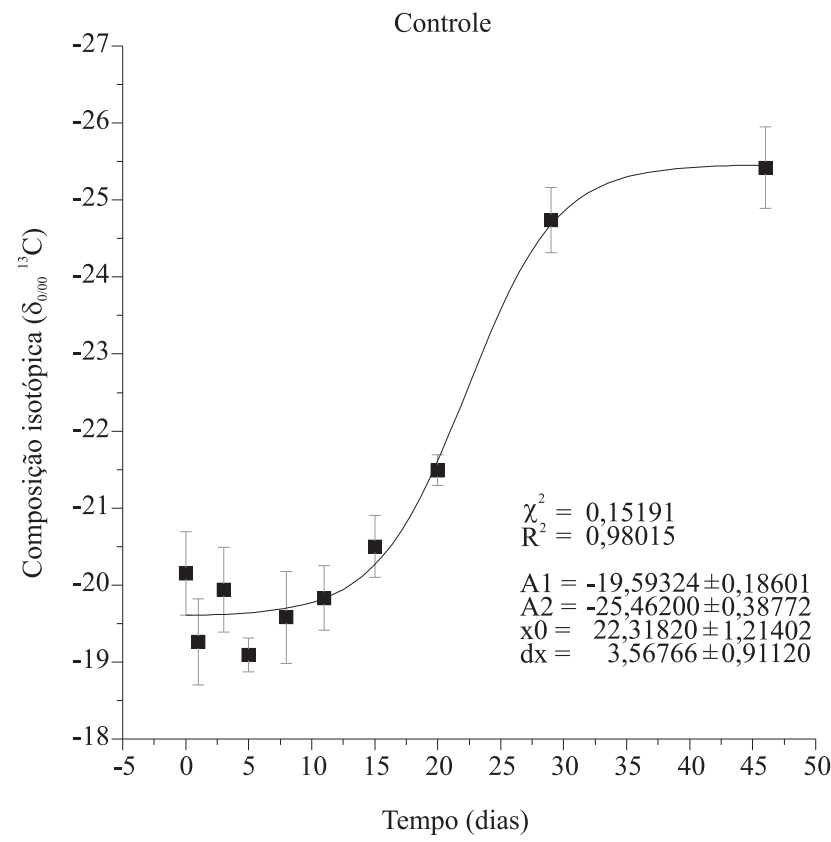

Atribuindo-se porcentual à equação gerada, pode-se determinar a contribuição porcentual de ração $\left(C_{3}\right)$ e, conseqüientemente, do leite $\left(\mathrm{C}_{4}\right)$ na composição do tecido adiposo dos leitões, em qualquer tempo.

\section{Resultados e Discussão}

Na Figura 1, observa-se a curva-padrão de distribuição dos valores de $\delta \%{ }^{13} \mathrm{C}$ do tecido adiposo dos leitões, ao longo do tempo, e a análise dos resultados pelo modelo de Boltzmann, em que se evidencia o turnover do carbono no tecido adiposo dos leitões, durante 46 dias após o desmame.

Verificou-se que os desvios-padrão foram relativamente altos, em grande parte das amostras analisadas. Gonzáles-Martin et al. (1999) observaram que os valores de $\delta \%{ }^{13} \mathrm{C}$ alteram-se de acordo com a profundidade da gordura subcutânea, e que isso é consequiência de diferenças no grau de insaturação das gorduras conforme sua profundidade no tecido. Tal fato poderia explicar, em parte, as grandes diferenças obtidas nos valores isotópicos entre animais do mesmo tratamento e do mesmo dia de abate, pois ao passar pela estufa, as diferentes frações (de diferentes profundidades) podem ter sido derretidas entre amostras de diferentes animais. Outra possível explicação é a

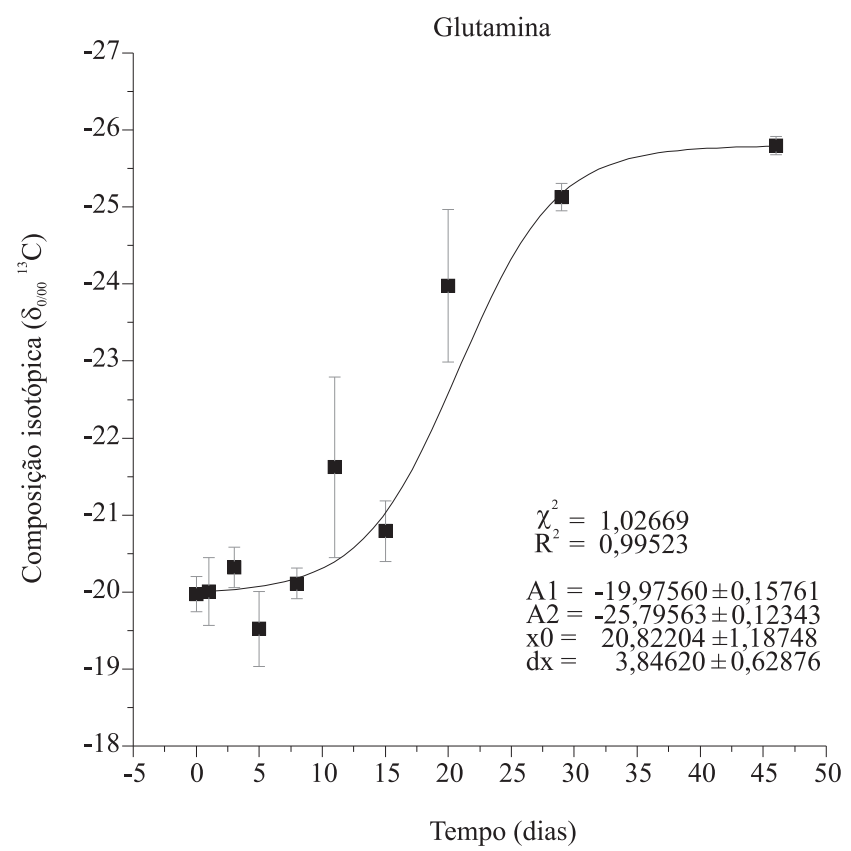

Figura 1. Composição isotópica do carbono $\left(\delta \%{ }^{13} \mathrm{C}-\right.$ média \pm desvio-padrão) do tecido adiposo de leitões, após o desmame, suplementados ou não com glutamina na ração, e análise dos resultados pelo modelo de Boltzmann. 
variação entre indivíduos na capacidade de deposição de gordura, pois alguns assimilam mais rápido o sinal isotópico da nova dieta em seu tecido adiposo do que outros.

As Figuras 2 e 3 apresentam a contribuição porcentual do carbono do leite (fonte pré-desmame) e da ração (fonte pós-desmame), na composição do tecido adiposo dos leitões, ao longo dos 46 dias após o desmame, para os tratamentos controle e glutamina, respectivamente.

O modelo sigmoidal de regressão de Boltzmann foi o que melhor explicou o comportamento dos resultados isotópicos. Atribuindo-se terminologia isotópica à equação geral do modelo, estimou-se a contribuição porcentual das fontes de alimentação dos leitões (pré e pósdesmame) na composição da gordura corporal.

No nascimento, o conteúdo de gordura corporal dos leitões é de aproximadamente $2 \%$ do peso corporal total, portanto, as reservas de energia se esgotam em poucas horas após o nascimento. Os altos teores de energia do colostro e do leite proporcionam o acúmulo de reservas de gordura, ao longo do período de aleitamento, que chegam de 12 a $15 \%$ do peso corporal ao desmame praticado entre a terceira e quarta semanas de idade (Bertol, 2000). No presente experimento, este fato tornou-se evidente, pelos valores isotópicos de carbono do tecido adiposo dos leitões ao desmame, que se assemelharam ao do leite produzido pelas suas mães, cujos valores se mantiveram em torno de $-18,87 \pm 0,24 \%$, durante toda lactação.

Roura (2004) afirma que o consumo de alimentos, por leitões desmamados com 3 a 4 semanas de idade,

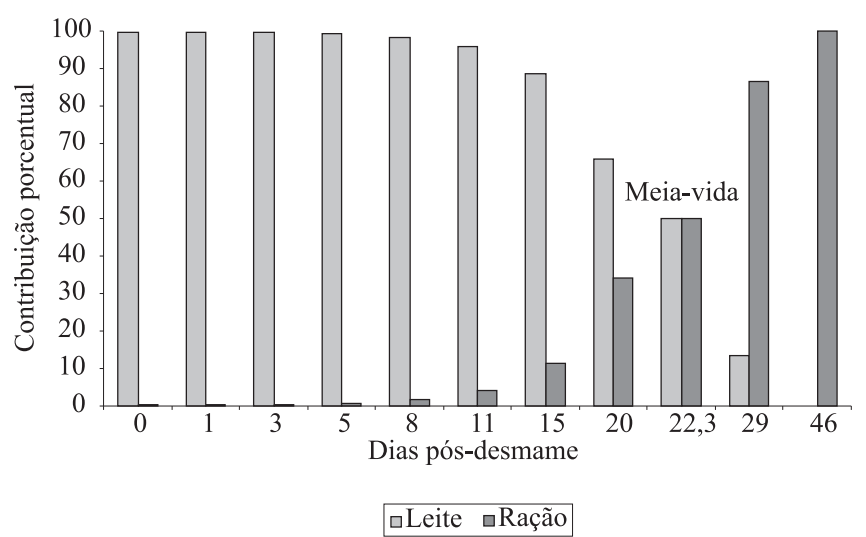

Figura 2. Contribuição porcentual do leite (aleitamento) e da ração (período pós-desmame), na composição em carbono da gordura (tecido adiposo) de leitões desmamados no tratamento-controle. encontra-se normalmente abaixo do necessário, para sua manutenção por cerca de dois dias ou mais. Em razão disso, ocorre significativa perda de peso, em conseqüência da mobilização de gordura corporal, provocada provavelmente pelo estresse e pelo baixo consumo de alimento nesse período.

Bertol et al. (2000) verificaram que o conteúdo médio de extrato etéreo corporal de leitões reduziu-se de 38,81 para 32,99\% do corpo vazio, e que a taxa de deposição diária de gordura em leitões, nos primeiros 14 dias após o desmame, foi negativa. Após o período crítico, a reserva de gordura corporal aumentou gradativamente. Resultados semelhantes foram obtidos por Close \& Steiner (1984), em diferentes condições de ambiente e alimentação.

Este fato poderia explicar a pequena alteração dos valores isotópicos do tecido adiposo, na primeira semana após o desmame, apesar de os leitões terem recebido ração com sinal isotópico distinto da fonte de alimentação anterior (leite), pois os animais, nesse período, usam suas reservas corporais de gordura para manutenção ao invés de depositá-las. Após esse período mais crítico, o tecido adiposo começou a incorporar o sinal isotópico da ração, o que indica início da deposição de gordura corporal.

Além disso, Stryer (1994) afirma que os hormônios catabólicos inibem a síntese de ácidos graxos, por manterem no estado fosforilado inativo a acetil CoA carboxilase, enzima regulatória-chave no metabolismo dos ácidos graxos. Segundo Worsae \& Schmidt (1980), o desmame em suínos está associado ao aumento nas concentrações plasmáticas de cortisol, o principal

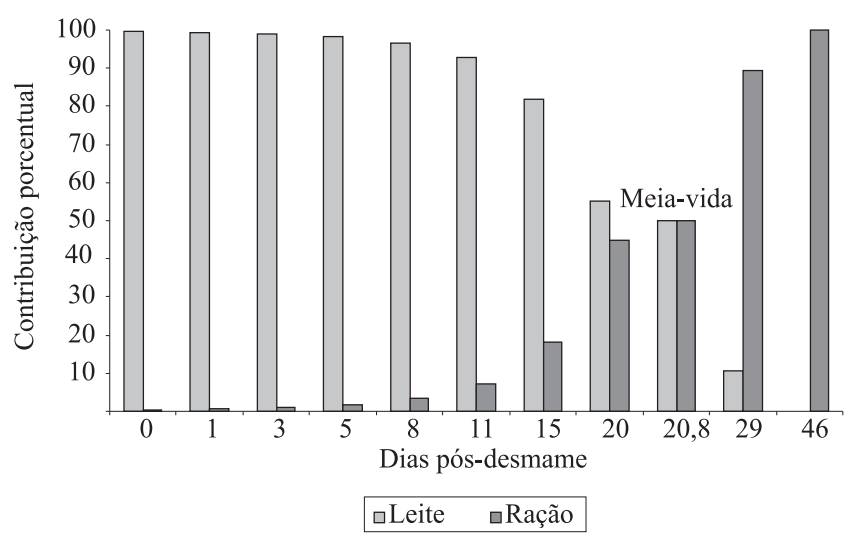

Figura 3. Contribuição porcentual do leite (aleitamento) e da ração (período pós-desmame), na composição em carbono da gordura (tecido adiposo) de leitões desmamados no tratamento com glutamina.

Pesq. agropec. bras., Brasília, v.42, n.11, p.1601-1607, nov. 2007 
glicocorticóide circulante em suínos. Portanto, este fato poderia estar associado ao consumo insuficiente de energia pelos leitões após o desmame, para o estímulo da lipólise e inibição da lipogênese nesse período.

Os resultados obtidos corroboram a afirmação de Stryer (1994) de que o metabolismo dos ácidos graxos é eficazmente controlado, de modo que a síntese e a degradação respondem bem às necessidades fisiológicas.

Verificou-se, porém, que para os animais alimentados com suplemento de glutamina, a incorporação do carbono proveniente da alimentação pós-desmame, no tecido adiposo, foi mais rápida, o que evidencia retomada na deposição de gordura corporal mais precoce nesse grupo de animais (Figuras 2 e 3 ).

Tal fato pode ser confirmado pelos valores de meiavida do carbono, obtidos $\left(\chi_{0}\right)$ para ambos os tratamentos, em que o tratamento com glutamina apresentou menor tempo, para que o tecido corporal avaliado atingisse a condição de $50 \%$ da concentração de cada dieta.

Baquet et al. (1991) verificaram que quando hepatócitos de ratos foram incubados na presença de $20 \mathrm{mM}$ de glicose, a glutamina foi o aminoácido de maior eficiência no estímulo da lipogênese. Efeitos semelhantes da glutamina sobre a lipogênese foram encontrados por Lavoinne et al. (1987).

Krause et al. (1996) afirmam que o estímulo da lipogênese por aminoácidos co-transportados por $\mathrm{Na}^{+}$ resultam da ativação da acetil-CoA carboxilase. Segundo estes autores, a ativação desta enzima pode ser mediada pelo estímulo de proteínas quinases, resultante do aumento no volume das células induzido pelos aminoácidos.

Segundo Hobson \& Clark (1992), o tecido adiposo é considerado um tecido de rápido metabolismo. Porém, os valores de meia-vida encontrados no presente experimento $-\mathrm{T}=22,3$ e 20,8 dias para os tratamentoscontrole e glutamina, respectivamente - refletem uma lenta incorporação do carbono, proveniente da dieta, no tecido adiposo animal. Isto pode ser explicado pelo fato de que na fase inicial do experimento, os animais encontravam-se sob balanço energético negativo e usavam suas reservas de gordura corporal, portanto a incorporação do carbono, proveniente da nova alimentação, em seu tecido adiposo, iniciou-se apenas após esse período.

As diferenças obtidas entre os tratamentos referemse à suplementação de $1 \%$ de glutamina na ração.
É provável que níveis de suplementação mais elevados deste aminoácido possam interferir de forma mais significativa no metabolismo do tecido adiposo.

\section{Conclusões}

1. A incorporação do carbono, proveniente da ração, no tecido adiposo dos leitões logo após o desmame, é mínima.

2. Após o período de desmame, o tecido começa a incorporar o sinal isotópico da nova alimentação, o que indica a retomada na deposição de gordura corporal.

3. A suplementação de $1 \%$ de glutamina, na ração de leitões desmamados, acelera a incorporação do carbono, proveniente da alimentação pós-desmame, no tecido adiposo.

\section{Referências}

BAQUET, A.; LAVOINNE, A.; HUE, L. Comparison of the effects of various amino acids on glycogen synthesis, lipogenesis and ketogenesis in isolated rat hepatocytes. Biochemical Journal, v.273, p.57-62, 1991.

BERTOL, T.M. Nutrição e alimentação dos leitões desmamados em programas convencionais e no desmame precoce. Concórdia: Embrapa Suínos e Aves, 2000. 44p. (Circular Técnica, 21).

BERTOL, T.M.; LUDKE, J.V.; MORES, N. Efeito de diferentes fontes protéicas sobre desempenho, composição corporal e morfologia intestinal em leitões. Revista Brasileira de Zootecnia, v.29, p.1735-1742, 2000.

CERSOSIMO, E.; WILLIAMS, P.; HOXWORTH, B.; LACY, W.; ABUMRAD, N. Glutamine blocks lipolysis and ketogenesis of fasting. American Journal of Physiology, v.250, p.E248-E252, 1986.

CLOSE, W.H.; STANIER, M.W. Effects of plane of nutrition and environmental temperature on the growth and development of the early-weaned piglet. 1. Growth and body composition. Animal Production, v.38, p.211-220, 1984.

FELLER, D.D. Adipose tissue. In: RENOLD, A.E.; CAHILL JUNIOR, G.E. (Ed.). Handbook of Physiology. Washington: American Physiological Society, 1965, p.363-373.

GONZÁLEZ-MARTIN, I.; GONZÁLEZ-PÉREZ, C.; HERNÁNDEZ MÉNDEZ, J.; MARQUÉS-MACIAS, E.; SANZ POVEDA, F. Use of isotope analyses to characterize meat from Iberian-breed swine. Meat Science, v.52, p.437-441, 1999.

HOBSON, K.A.; CLARK, R.G. Assessing avian diets using stable isotopes I: turnover of ${ }^{13} \mathrm{C}$ in tissues. The Condor, v.94, p.181-188, 1992.

KOWALCHUK, J.M.; CURI, R.; NEWSHOLME, E.A. Glutamine metabolism in isolated incubated adipocytes of the rat. Biochemical Journal, v.249, p.705-708, 1988. 
KRAUSE, U.; RIDER, M.H.; HUE, L. Protein kinase signaling pathway triggered by cell swelling and involved in the activation of glycogen synthase and acetyl-CoA carboxylase in isolated rat hepatocytes. Journal of Biological Chemistry, v.271, p.1666816673, 1996.

LAVOINNE, A.; BAQUET, A.; HUE, L. Stimulation of glycogen synthesis and lipogenesis by glutamine in isolated rat hepatocytes. Biochemical Journal, v.248, p.429-437, 1987.

MAVROMICHALIS, I. Research into practice. Pig Progress, v.17, p.32, 2001.

METGES, C.; KEMPE, K.; SCHIMIDT, H.L. Dependence of the carbon isotope contents of breath carbon dioxide, milk, serum and rumen fermentation products on the $\delta^{13} \mathrm{C}$ value of food in dairy cows. British Journal of Nutrition, Cambridge, v.63, p.187-196, 1990.

MICROCAL SOFTWARE ORIGIN 6.0 PROFESSIONAL. Origin Data Analysis and Technical Graphics. USA: Microcal Software Inc., 1999.

NATIONAL RESEARCH COUNCIL. Nutrient requirement of swine. $10^{\text {th }}$ ed. Washington: National Academy of Sciences, 1998. 189 p.
NEWSHOLME, E.A.; LEECH, A.R. Biochemistry for the Medical Sciences. New York: John Willey \& Sons, 1983.

ROURA, E. Changes in piglet feeding behaviour at weaning: digestive development and dietary factors. In: CONGRESSO LATINO AMERICANO DE SUINOCULTURA, 2., 2004; CONGRESSO DE SUINOCULTURA DO MERCOSUL, 4., 2004, Foz do Iguaçu. Anais. Foz do Iguaçu, 2004. p.115-124.

STRYER, L. Metabolismo de ácidos graxos. In: STRYER, L. Bioquímica. 4ed. Rio de Janeiro: Guanabara, 1994. p.571-595.

TISCHLER, M.E.; GOLDBERG, A.L. Leucine degradation and release of glutamine and alanine by adipose tissue. Journal of Biological Chemistry, v.255, p.8074-8081, 1980.

TIZIANELLO, A.; DEFERRARI, G.; GARRIBOTTO, G. Effects of chronic renal insufficiency and metabolic acidosis on glutamine metabolism in man. Clinical Science and Molecular Medicine, v.55, p.391-397, 1978.

WORSAE, H.; SCHMIDT, M. Plasma cortisol and behaviour in early weaned piglets. Acta Veterinaria Scandinavica, v.21, p.640$657,1980$.

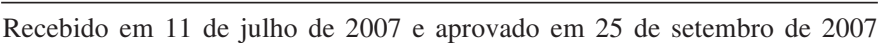

